\title{
Çoklu Çarpan Jetli Dikdörtgen Kanalda Yüzey Isı Geçişinin Deneysel Araştırılması
}

\author{
${ }^{1}$ Dr. Öğr. Üyesi Ünal UYSAL ve * 2 Metin SÖZBIR \\ ${ }^{1}$ Sakarya Üniversitesi Mühendislik Fakültesi Makine Mühendisliği Bölümü 54187 Serdivan, Sakarya, \\ *2Sakarya Üniversitesi Fenbilimleri Enstitüsü Makine Eğitimi A.B.D. 54187 Serdivan, Sakarya,
}

\section{Özet :}

Gaz türbinleri savunma sanayiinde ve elektrik enerjisi üretiminde yaygın şekilde kullanılan sistemlerdir. Gaz türbininin türbin giriş sıcaklığ 1 yeni modellerde $1700^{\circ} \mathrm{C}$ $2200^{\circ} \mathrm{C}^{\prime}$ ye yaklaşmaktadır. Gaz türbin giriş sıcaklığının artması, aynı zamanda türbin kanatları ile sıcak gaz yolu üzerindeki diğer ekipmanların maruz kaldığı mekanik ve 1sıl zorlamaların etkisini de ciddi ölçüde arttırmakta; bundan en çok nasibi türbin kanatları almaktadır. Gaz türbinlerinin ömürleri, türbin bakımına ve türbin kanatlarının ömürlerine bağlıdır. Bu yüksek sıcaklıklara karşın türbin kanatçıklarının, 1sıl şoklardan veya 1sıl gerilmelerden korunması ve güvenli şekilde çalışmasını sürdürebilmesi maksadıyla soğutulması zarureti ortaya çıkmaktadır. Tasarımcılar bu soğutma kanallarının geliştirilmesi için farklı geometrik kesitli kanal ile kanal içinde rip konfigürasyonu v.s. alanlarda çarpmalı jet ve çapraz akışın arttırılması hususunda araştırmalar yapmaktadır. Bu çalışmada bir jet plaka üzerinde $5 \times 10$ sıralı, toplamda 50 adet, 3 farklı hidrolik çaplı çarpan dairesel jetlerin olduğu ve jet-hedef plakalar arasında 3 farklı aralıkta oluşan hedef plaka yüzeylerinin 1sı geçiş dağılımı dört farklı debilerde ve Reynolds sayısında deneysel olarak araştırılmıştır. Yüzeydeki ısı geçiş katsayısı dağılımını tespit etmek için Sakarya Üniversitesi Makine Mühendisliği Laboratuvarı'nda kurulu bulunan TLC (Termokromik Sıv1 Kristal) deney düzeneği ve modeli kullanılmıştır. Yapılan çalışmalar sonucunda jet-hedef plaka aralığının ve jet çaplarının ısı geçiş katsayısının dağılımını etkilediği tespit edilmiştir.

Anahtar Kelimler: Isı geçiş katsayısı dağılımı, sıvı kristal termografisi, gaz türbinlerinin soğutulması.

\section{Giriş}

Gaz türbinleri teknolojik olarak çağımızda enerji üreten en üst düzey makinelerdir. Gaz türbinleri savunma sanayiinde özellikle; uçak ve helikopter gibi süratli araçlar ile elektrik santralleri ve gemi motorlarında enerji üretmek için kullanılmaktadır. Gaz türbini malzemesinin gelişmesi malzeme teknolojisindeki gelişmelerle parallellik teşkil etmektedir. Malzeme teknolojisi oldukça ileri düzeylere ulaşmasına rağmen gaz türbinlerinin giriş sıcaklıkları, kanat malzemelerinin dayanma sıcaklıklarından çok daha yüksektir. Gaz türbin giriş sıcaklığının artması, aynı zamanda türbin kanatları ile sıcak gaz yolu üzerindeki diğer ekipmanların maruz kaldığı, mekanik ve 1sıl zorlamaların etkisini de ciddi ölçüde arttırmakta; bundan en çok nasibi türbin kanatları almaktadır. $\mathrm{Bu}$ yüksek sıcaklıklara karşın türbin kanatçıklarının, 1sıl şoklardan veya 1sıl gerilmelerden

* Sorumlu yazar: Adres: Mühendislik Fakültesi, Makine Mühendisliği Bölümü Sakarya Üniversitesi, 54187, Sakarya TÜRKIYE. E-posta adresi: uysal@sakarya.edu.tr, Tel: +902642955849 
korunması ve güvenli bir şekilde çalışmasını sürdürebilmesi maksadıyla soğutulması zarureti ortaya çıkmaktadır. Birçok türbin kanatçığı soğutma tekniği mevcutsa da kompresörden alınan havayla yapılan soğutma en yaygın ve en çok kullanılan soğutma tekniğidir. Bu nedenle, ileri malzeme teknolojisi ile üretilen türbin kanatlarının da mutlak surette soğutulması gerekmektedir. Soğutmanın bu denli önemli olması, gaz türbini üreticilerini özellikle kanat soğutma teknolojileri konusunda yoğun araştırmalar yapmaya yöneltmiştir.

Gaz türbini kanatlarında soğutmanın artırılmasında kanat içerisindeki iç kanalların kullanılması son derece önemlidir. Özellikle türbinlerin birincil kanatlarının soğutulması için farklı geometrilerde ve farklı kombinasyonlarda iç geçiş kanalları kullanılmaktadır. Tasarımcılar bu soğutma kanallarının geliştirilmesi için farklı geometrik kesitli kanal ile kanal içinde rip konfigürasyonu v.s. alanlarda çarpmalı jet ve çapraz akışın arttırılması hususunda araştırmalar yapmışlardır [1-5]. Türbin kanatlarının ömürlerini artırmak ve çalışma güvenliğini sağlamak; türbin kanadında meydana gelen aşırı ısı yükünün alınması iç ve dış soğutma teknikleri ile mümkün olmaktadır. Soğutma yöntemlerinin daha ucuza mal edilmesi tercih olarak ön plana çıkmaktadır. Bundan dolayı tasarımcıların ilgi odağı gaz türbinlerinin soğutma yöntemleri olmaktadır. Bu durum göz önüne alındığında; türbin kanat malzemesinin iyileştirilmesi, kanat kaplamaları ve kanat soğutma yöntemleri konuları üzerinde mühendislik çalışmaları yoğunlaştırılmıştır.

Bu tez çalışmasında; gaz türbin problemlerinden birisi olan kanatların soğutulması kapsamında gaz türbin kanatları içindeki soğutma kanallarına benzeyen bir modül oluşturularak; bir jet plaka üzerinde 5 siral, her sirada 10 adet, toplamda 50 adet jet dairesel geometrisine sahip hidrolik çapları (2.5 mm, $5 \mathrm{~mm}$ ve 7,5 mm) aynı olan kanallarda ve jet-hedef plakalar arasında $10 \mathrm{~mm}, 15$ $\mathrm{mm}$ ve $20 \mathrm{~mm}$ aralık olan hedef plaka yüzeyinin ısı geçişi dört farklı debi $\left(20 \mathrm{~m} / \mathrm{h} ; 30 \mathrm{~m}^{3} / \mathrm{h} ; 40 \mathrm{~m}^{3} / \mathrm{h}\right.$; $50 \mathrm{~m}^{3} / \mathrm{h}$ ) ve Reynolds sayısinda siv1 kristal termografisi metodu kullanilarak deneysel incelenmiştir. $\mathrm{Bu}$ çalışmanın konusu hidrolik çapları değişen çarpmalı jet geometrilerinden oluşmuş bir hedef ve jet yüzeylerinde en homojen 1sı geçişini sağlamaktır. Bu nedenle çarpmalı jetin büyüklüğü, geometrisi ve iki yüzey (alt-jet ve jet-hedef) plaka arasındaki uzaklıklar önemlidir. Isı geçiş büyüklüklerinin yüzeyde homojen olması istenmekte böylece 1sınan yüzeyin homojen bir soğutma-1sıtma işlemine tabi tutulduğunu göstermektedir. Yüzeydeki 1sı geçiş katsayısı dağılımını tespit etmek için Sakarya Üniversitesi Mühendislik Fakültesi Makine Mühendisliği Bölüm Laboratuvarında kurulu bulunan TLC (Termokromik Sıvı Kristal) deney seti ve iki kademeli tasarlanan türbin kanat modülü kullanılmıştır. Bu çalışmada LCR Hallcrest,IL/USA tarafindan imalatı ve kalibrasyonu yapılan R35C5W-tipli TLC kullanılmıştır. LCIA (Liquid Crystal Imaning Analayser) programı USA Pittsburgh Üniversitesi Makine Mühendisliği Bölümü tarafından geliştirilmiştir. Deney düzeneğinin çeşitli noktalarına bağlı termoçift elemanlardan alınan sıcaklık değerleri veri toplama kartı ile kaydedilmiş, renk profili kullanılarak yüzeydeki sıcaklık dağılımı ve 1sı transfer katsayısı hesaplanabilmiştir. Çalışmanın amacı en homojen, en az basınç kaybına neden olan ve en yüksek zorlanmış ısı geçişi katsayısına sahip olan sistem konfigürasyonun tespit edilmesidir.

\section{Deneysel Çalışma}

Bu çalışmada türbin kanatlarında kullanılan geçiş parçaları, geçişli kanalları ve bunlarda kullanılan çarpmalı jet geometrileri üzerine odaklanılmıştır. Çalışmada; dairesel jet geometrisine sahip 
dikdörtgen kesitli kanallarda 1sı transferinin TLC metodu kullanılarak deneysel olarak incelenmesi hedeflenmiştir. Deneyde gaz türbin kanatları içindeki soğutma kanallarına benzeyen bir modül oluşturulmuştur. Modül şeffaf renkte fleksiglas malzemeden yapılmış ve plakalar (alt, jet, hedef) $10 \mathrm{~mm}$. kalınlığında, ara parça 3 farklı $(10 \mathrm{~mm}, 15 \mathrm{~mm}, 20 \mathrm{~mm})$ ebattadır. Modülün ucunda yarım parmak manşona bağlı huni şeklinde paslanmaz metal malzemeden verilen hava ile modülün kısa kenar ucundan hava girişi yapılmakta, dairesel jet geometrili kanallardan geçerek alta/ikinci kademeye doğru akış sağlanmakta; modülün uzun kenarından L $\left(90^{\circ}\right)$ dönüşü yaparak hava tahliye edilmektedir (şekil 1.).
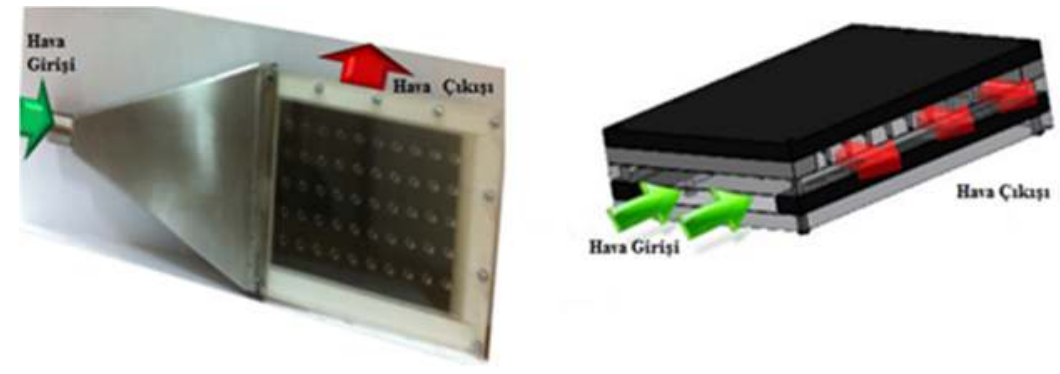

Şekil 1. Deney modülü ve 3D resmi hava akışı gösterimi..

\subsection{Deney Düzeneği}

Deney düzeneği 4 ana bölümden meydana gelmektedir (şekil 2.). Birinci bölümde, basınçlı hava kaynağı olarak kullanılan kompresör, hava kontrol vanası, havayı temizlemek için kullanılan bir hava filtresi, havayı 1sıtmak için kullanılan boru içi 1sıtıcılar, 1sıtıcıyı hassas bir şekilde ayarlayabilmek için ısıtıcıya bağlı bir gerilim ayarlayıcı, borudan gelen havanın debisini ve boru içindeki akışkan sıcaklığını ölçmek için kullanılan bir debimetre, basınç ve hava debisini ölçmek için manometre, iki adet selonoid valf ile bypass hattı ve 1sıtıcılar ile valflerin bağlı olduğu ve bu valflerin açılıp kapanmasını sağlayan anahtarların bağlı bulunduğu kontrol bölümü, test bölümünden önce bulunan ve akışı düzgünleştirmek için kullanılan bir difüzör bulunmaktadır.

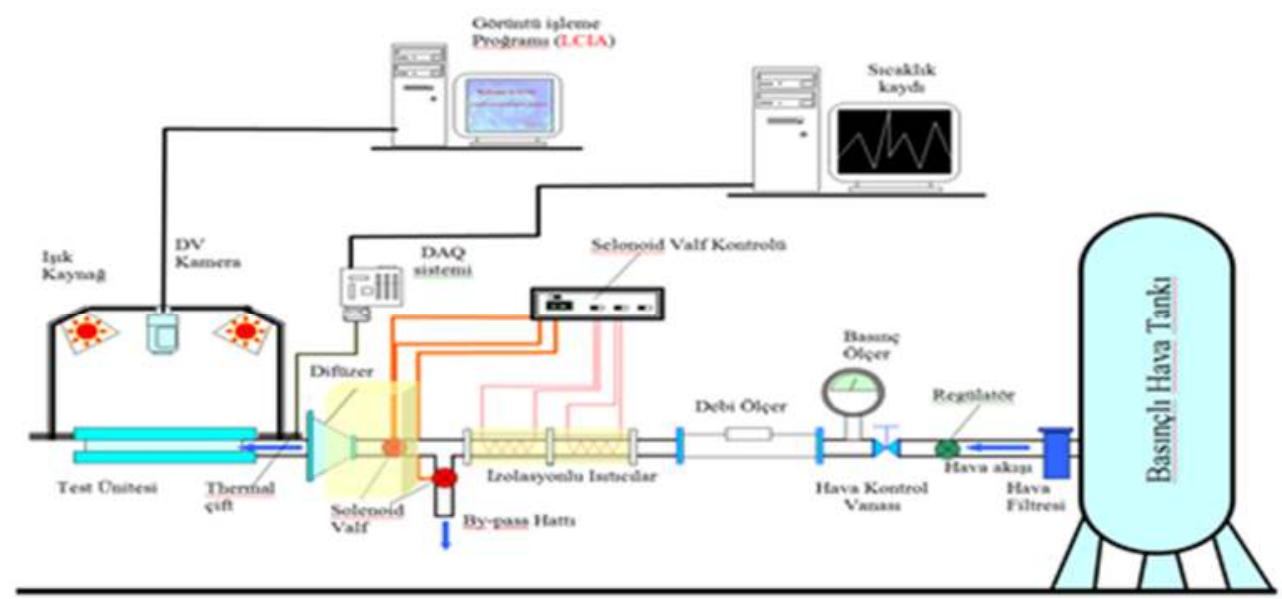

Şekil 2. Deney düzeneğinin şematik gösterimi.

İkinci bölümde TLC’lerin renk değişimlerini kayıt edeceğimiz bir adet DV kamera, iki adet yüksek 
wattlı 1şık kaynağı bulunmaktadır. İyi bir görüntü için test bölümünün alt tarafı, 1şık kaynaklarının üst tarafı ve test bölümündeki parlayan her şey siyah örtü ve özel bir bant ile kaplanmıştır. Üçüncü bölümde, test bölümünün giriş ve çıkış sıcaklıklarını, hava sıcaklığını deney süresince ölçen ve bir PC yardımıyla kayıt eden veri toplama sistemi (DAQ) ile termoçiftler bulunmaktadır. Buradan alınan verilerle yüzeyin ısı transferi özelliklerini LCIA(Liquid Crystal Imaging Analyzer) yazılımı ile bulmak mümkün olmuştur. Dördüncü bölümde ise; test bölümü bulunmaktadır.

\subsection{Deney Belirsizliği}

Test yüzeyinde meydana gelen belirsizlik \%0.5, giriş sıcaklığında meydana gelen belirsizlik \%0.4 ve çıkış sıcaklığında meydana gelen belirsizlik \%1'dir. Sıcaklık ölçümlerinin toplam belirsizliği $\pm 0.2{ }^{\circ} \mathrm{C}$ dir. Ayrıca diğer belirsizlikler sıvı kristalin renk kalibrasyon sıcaklığı, renk değişimi sıcaklığı ve katı malzemenin termal difüzivitesinde meydana gelen hatalar yaklaşık olarak \% $\%, \% 4$, \%1 şeklindedir. Diğer büyük bir belirsizlik ise deneye gönderilen hava debisi ve Reynolds sayısındaki ölçüm hataları yaklaşık olarak \%4 olarak alınabilir. Isı transferi katsayısına tüm bu hataların toplanmasıyla etki eden hata oran $\%$ olarak hesaplanabilir.

\section{Deneysel Çalışmalar}

Deneyler her bir jet hidrolik çapı ve ara geçiş parçası kalınlığı olmak üzere dört farklı debide ve Re sayısında gerçekleştirilmiştir (tablo 1).

Tablo $1.10 \mathrm{~mm}, 15 \mathrm{~mm}$ ve $20 \mathrm{~mm}$ aralık için kanal için Re sayısı.

\begin{tabular}{|c|c|c|c|c|c|c|c|c|c|}
\hline \multirow{3}{*}{$\begin{array}{l}\text { 픙 } \\
\frac{3}{3}\end{array}$} & \multirow{3}{*}{$\frac{\frac{\vec{F}}{\mathfrak{E}}}{\frac{E}{2}}$} & \multicolumn{4}{|c|}{ Re_giris } & \multicolumn{4}{|c|}{ Re_cukıs } \\
\hline & & \multicolumn{3}{|c|}{ Dikdörtgen Kanal Kesit Alane (mm²) } & \multirow{2}{*}{ Jet } & \multicolumn{3}{|c|}{ Dikdörtgen Kanal Kesit Alanı (mm) } & \multirow{2}{*}{ Jet } \\
\hline & & $(120 \times 10)$ & $(120 \times 15)$ & $(120 \times 20)$ & & $(170 \times 10)$ & $(170 \times 15)$ & $(170 \times 20)$ & \\
\hline \multirow{4}{*}{$\begin{array}{l}E \\
E \\
\text { Ẽ } \\
\text { I }\end{array}$} & 20 & 4005.368954 & 357.021956 & 172 & 836.374573 & 66467 & 814.583589 & 2740.5156 & 573 \\
\hline & 30 & 6008.053431 & 5785.532934 & 5578.9067 & 59 & 4339.1497 & 4221.875384 & 4110,7734 & 254.561859 \\
\hline & 40 & 8010.737908 & 7714.043912 & 7438.5423 .44 & 5672.749145 & 5785.532934 & 5629.167179 & 5481.0312 & 5672.749145 \\
\hline & so & 10013,42239 & 9642,55489 & 7929 & 131 & 7231 & 703 & 89001 & 6431 \\
\hline \multirow{4}{*}{$\begin{array}{l}\text { EE } \\
\text { E⿱ } \\
\text { م' }\end{array}$} & 20 & 686 & 87 & & 286 & 101 & 768 & 46801 & \\
\hline & 30 & 14018.79134 & 13499.57685 & $13017 \cdot 4491$ & 212 & 1012 & 985 & 959 & 29 \\
\hline & 40 & 16021.47582 & 15428,08782 & 14877.08469 & 2836,374573 & 11571.06587 & 11258.33436 & 10962,0624 & 2836.374573 \\
\hline & 50 & 18024. & 173 & 16736,72027 & 8216 & 13017,4491 & 12665.62 & 12332.3202 & 16 \\
\hline \multirow{4}{*}{$\underset{2}{E}$} & 20 & 20026.84477 & 19285.10978 & 18596.35586 & 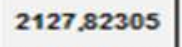 & 14463,83233 & 14072,91795 & 13702.578 & 2127.82305 \\
\hline & 30 & 22029.52925 & 21213,62076 & 20455.99144 & 3191,734575 & 15910.21557 & 15480.20974 & 15072,8358 & 3191.734575 \\
\hline & 40 & 24032,21373 & 23142,13174 & 22315.62703 & 4255.6461 & 17356.5988 & 16887.50154 & 16443.0936 & 4255.6461 \\
\hline & so & 26034,8982 & 25070,64271 & 24175,26262 & 5319,557625 & 18802,98203 & 18294.79333 & 17813,3514 & 5319.557625 \\
\hline
\end{tabular}

Resim ve grafik isimlendirilmesinde; plaka aralığ $10 \mathrm{~mm}$; jet hidrolik çapı daire $2,5 \mathrm{~mm}$; debi 20 $\mathrm{Nm}^{3} / \mathrm{h}$ olan deney modülü G10_D25_Q20 şeklinde yazımlanmıştır. Elde edilen sayısal ve deneysel veriler birbiriyle karşılaştırmalı olarak analiz edilmiştir. Verilerin değerlendirilmesinde temel olarak dört tür yaklaşım uygulanmıştır. Bunlar sırasıyla; 

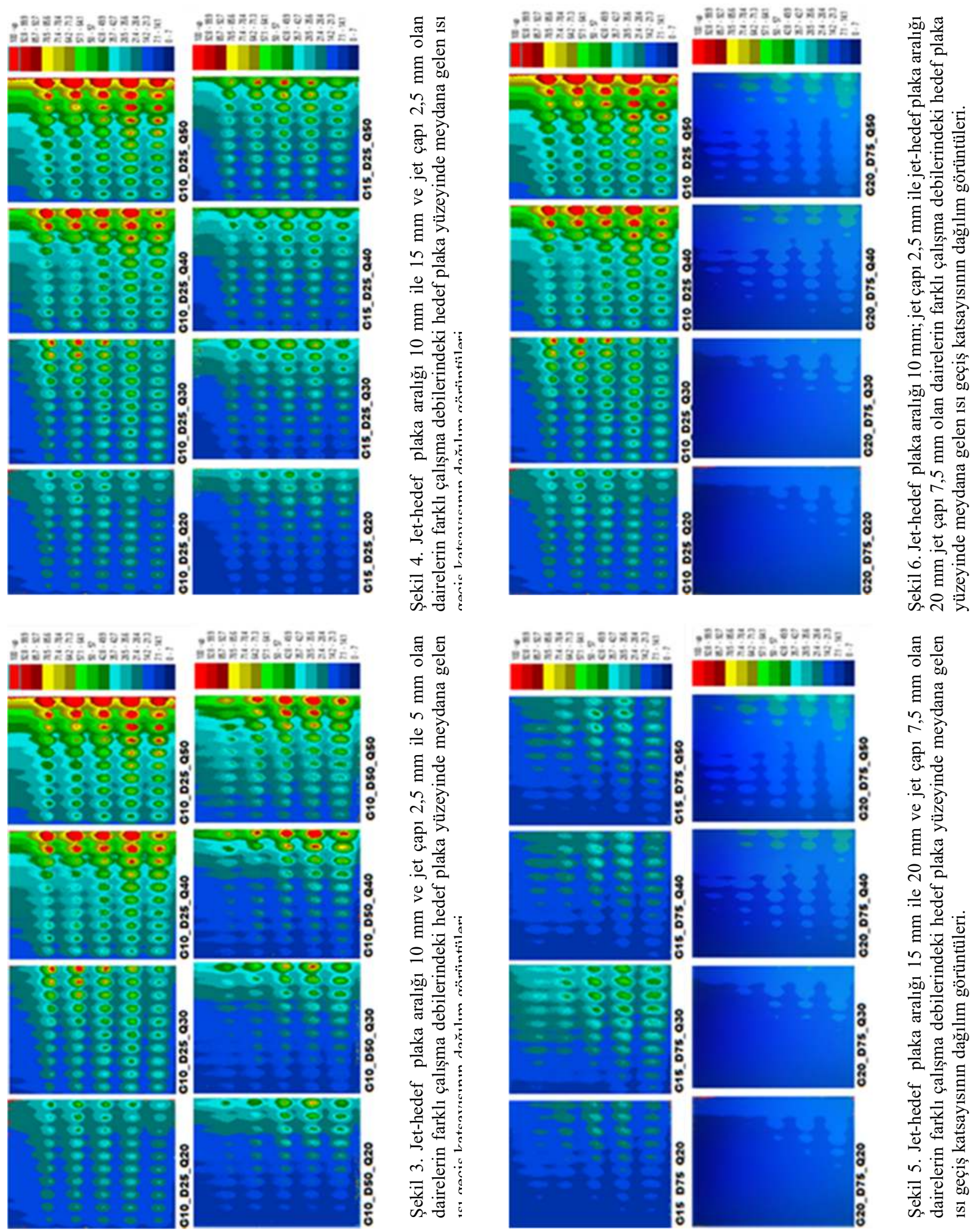

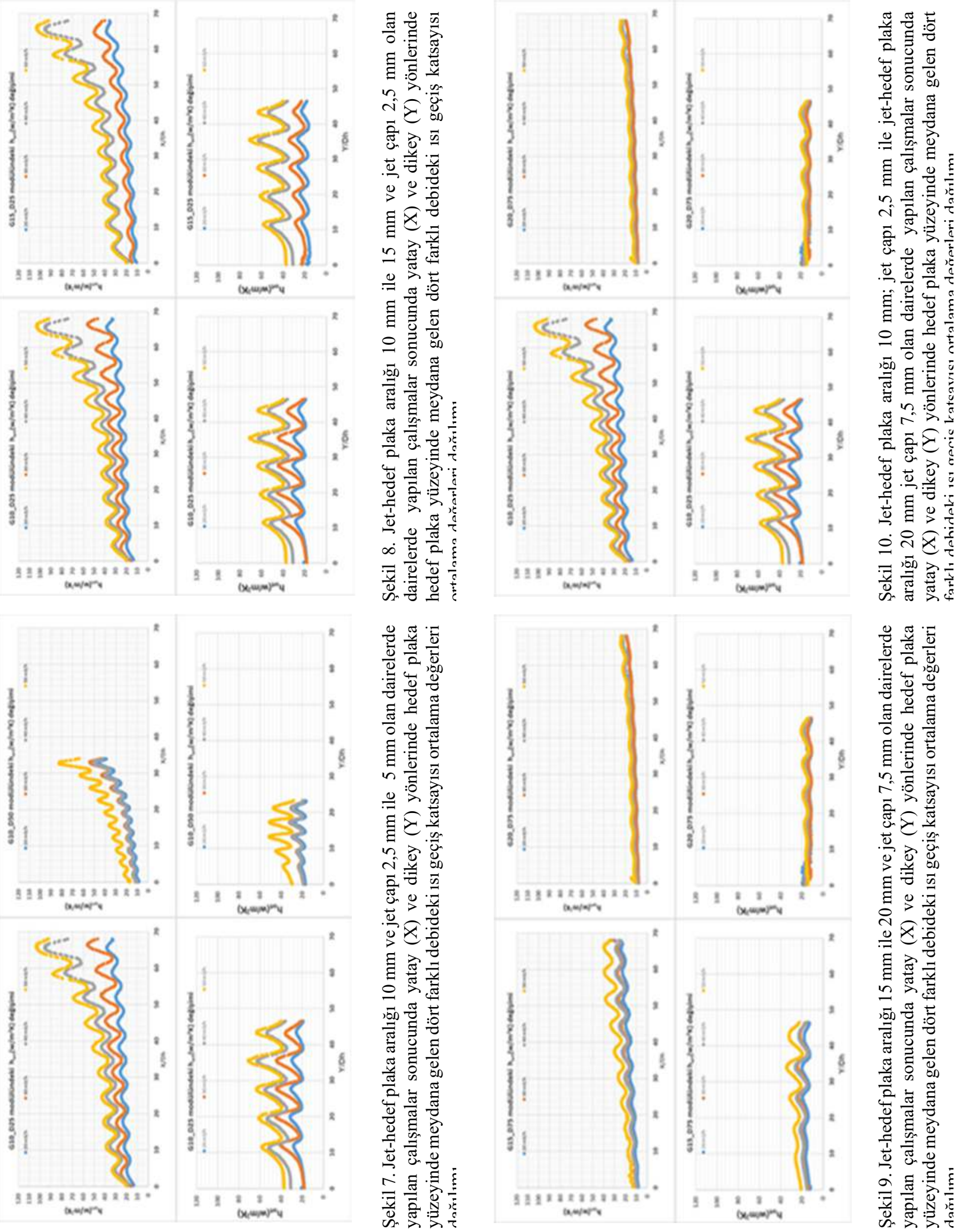
Jet-hedef plaka aralığg $10 \mathrm{~mm}$ ve jet çapı 2,5 mm ile 5,0 mm çaplı sıralı jet plakaları ile yapılan çalışmalar sonucunda farklı çalışma debilerinde her jetin X-Sutun ve Y-Kolon boyunca h_ort değişim grafikleri Şekil 3.10'da sunulmuştur.
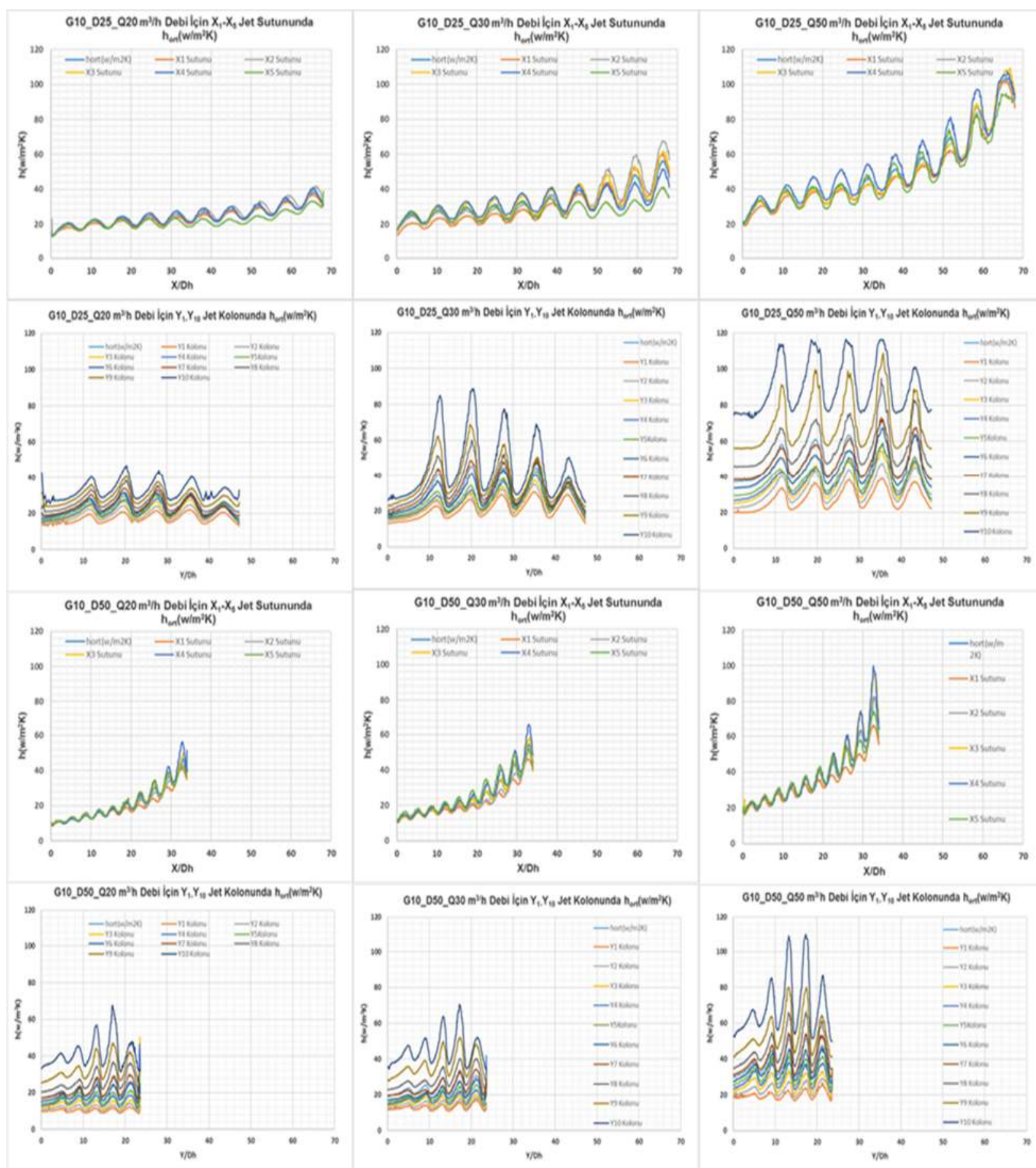

Şekil 11. Jet-hedef plaka aralığı $10 \mathrm{~mm}$ ve $2,5 \mathrm{~mm}$ ile $5,0 \mathrm{~mm}$ çaplı olan dairelerin farklı çalışma debilerinde her jetin $\mathrm{X}$-Sutun ve Y-Kolon boyunca h_ort değişim grafikleri. 
Jet-hedef plaka aralığ $10 \mathrm{~mm}, 15 \mathrm{~mm}$ ile $20 \mathrm{~mm}$ ve jet çap $2,5 \mathrm{~mm}, 5,0 \mathrm{~mm}$ ile 7,5 mm çaplı sıralı jet plakaları ile yapılan çalışmalar sonucunda farklı çalışma debilerinde Nu sayısı değişim grafikleri Şekil 3.12.'de sunulmuştur.
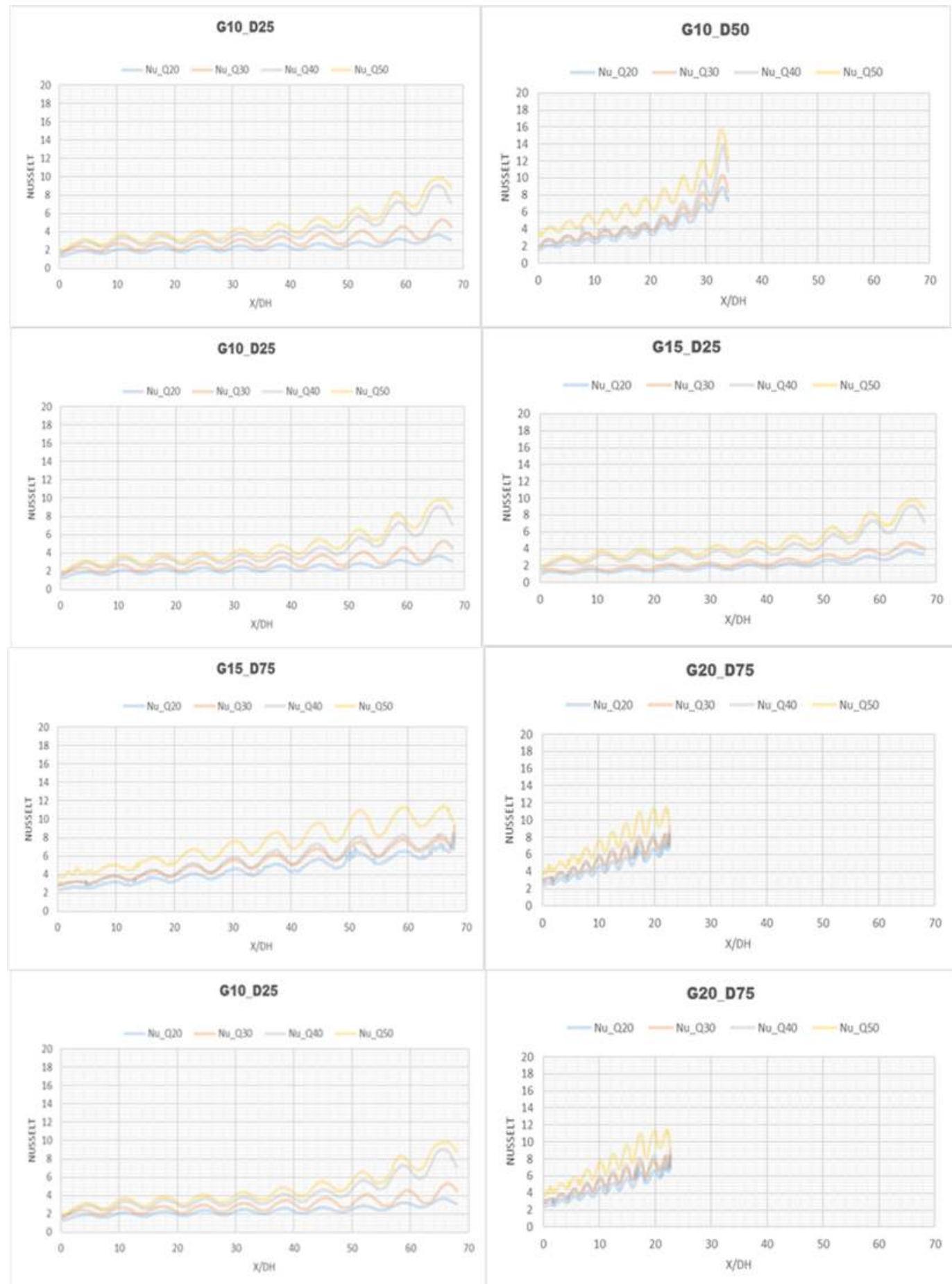

Şekil 12. Jet-hedef plaka aralığı $10 \mathrm{~mm}, 15 \mathrm{~mm}$ ile $20 \mathrm{~mm}$ ve jet çapı 2,5 mm, 5,0 mm ile 7,5 mm çaplı sıralı jet plakaları ile yapılan çalışmalar sonucunda farklı çalışma debilerinde Nu sayısı değişim grafikleri. 


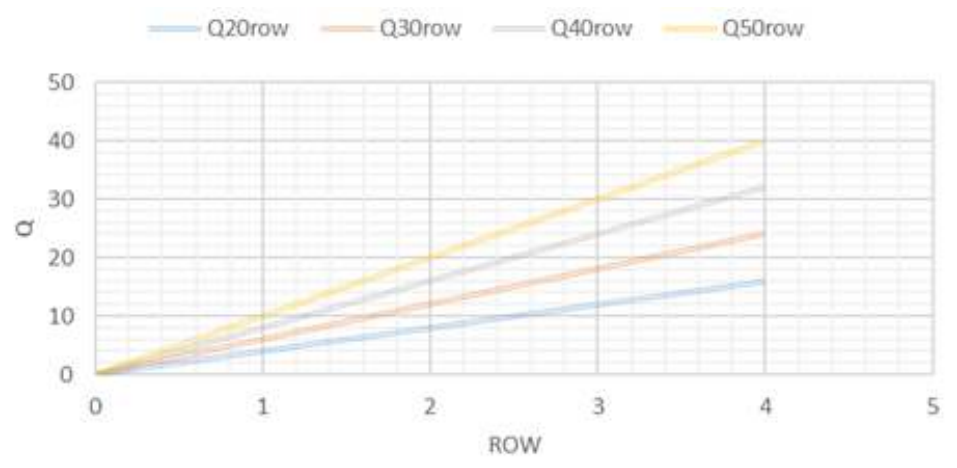

Şekil 13. Dört farklı debide yapılan çalışmalar sonucunda Çapraz Akış değişim grafikleri.

\section{Sonuçlarin Analizi ve Değerlendirilmesi}

Genel olarak deneysel çalışmalardan elde edilen görüntüler ve şekiller incelendiğinde;

Isı geçiş dağılımının Reynolds sayısının artmasıyla (hava debisinin) arttı̆̆ı görülmektedir. Jet çapının küçük olduğu durumlarda Re sayısının debilere göre doğrusal arttığı gözlenmiştir. Çarpan jetlerin bulunduğu hedef plaka bölgelerinde daha yüksek 1sı geçiş katsayısı meydana geldiği, akış doğrultusunda (kanal çıkışı) 1sı geçiş katsayısında lineer bir azalma meydana geldiği tespit edilmiştir. Isı geçiş katsayısındaki azalmanın \%20-25 aralığında olduğu tespit edilmiştir. Jet çaplarının artması hedef plaka yüzeyinde meydana gelen 1sı geçiş katsayısının azalmasına ve jethedef plaka arasındaki mesafenin artmasınında hedef plaka yüzeyinde meydana gelen isı geçiş katsayısının azalmasına neden olduğu tespit edilmiştir. Jet çapının küçülmesinin 1sı iletim katsayısını arttırdığı, jet-hedef plaka arasındaki aralığın azaltılmasının ise 1sı geçiş katsayısını arttırdığı tespit edilmiştir. Akışkanın jet plakanın arkasındaki kanal üzerinden gönderilmesi ve jethedef plaka arasındaki kanal çıkışının $90^{\circ} \mathrm{C}$ olması nedeniyle kanal hava girişinin olduğu bölgede en yüksek 1sı geçiş katsayısı meydana gelirken kanal çıkışına doğru 1sı geçiş katsayısının azaldığı tespit edilmiştir (Şekil 3, 4, 5, 6).

Jet-hedef plaka aralığ $10 \mathrm{~mm}$ ve jet çapı 2,5 $\mathrm{mm}$ ile 5,0 $\mathrm{mm}$ olan dairelerin farklı çalışma debilerinde y doğrultusunda 1Sı geçiş katsayı ortalamalarının değişmediği ve sinüs dalgasına benzeyen bir karekteristik yapıda olduğu ancak debinin artmasıyla jet bölgelerindeki pik değerlerinin arttığı Şekil 7'den; jet-hedef plaka aralığ $10 \mathrm{~mm}$ ile $15 \mathrm{~mm}$ ve jet çap1 2,5 mm olan dairelerin hedef plaka yüzeyinde meydana gelen 1S1 geçiş katsayısı ortalama değerleri dağılım grafiklerinin Şekil 7 ile hemen hemen aynı parelel yapıda olduğu Şekil 8'den; jet-hedef plaka arasındaki mesafe ile jet çaplarının artmasınında hedef plaka yüzeyinde meydana gelen ısı geçiş katsayısının azalmasına neden olduğu Şekil 9 ve 10'dan tespit edilmiştir. Buna karşın $\mathrm{x}$ doğrultusundaki ortalama 1sı geçişi değişimlerinin kanal akışı doğrultusunda kademeli bir şekilde azaldığı ve kanal çıkışında minumum değerlere ulaştığı ancak jet bölgelerinde en yüksek 1sı geçişi değerlerine ulaştı̆̆ Şekil 3, 4, 5, 6, 7'de görülmektedir. Jet-hedef plaka aralığ $10 \mathrm{~mm}$ ve jet çap1 2,5 mm olan jete ait değerlerin; jet-hedef plaka aralığ $10 \mathrm{~mm}$ ve jet çap1 5,0 mm olan jet ile jethedef plaka aralığı $15 \mathrm{~mm}$ ve jet çapı $2,5 \mathrm{~mm}$ ait değerlerden daha yüksek olduğu anlaşılmıştır. Jet-hedef plaka arasındaki mesafenin $20 \mathrm{~mm}$ ve daha fazlası ile jet çaplarının $\quad 7,5 \mathrm{~mm}$ ve daha 
fazlasının çalışmalara katkı sağlamayacağ 1 ve zaman ve emek sarfina neden olacağ değerlendirilerek bu aralıklardaki çalışmalara ara verilmiştir.

Şekil 11'de kanal içinde 5 sıralı ve 10'arlı olarak dizilmiş jetlerin her birinin yatay ve dikey doğrultudaki ortalama 1sı geçişleri gösterilmektedir. Bu grafikler incelendiğinde $\mathrm{X}$ yönünde her bir jet sırasının 1Sı geçiş katsayı ortalama değişimlerinin birbirlerine çok benzediği ancak kanal çıkışına doğru genel bir düşme eğiliminde olduğu tespit edilmiştir. Y yönündeki değişimlerde ise jet bölgelerinde en yüksek değere ulaştıkları ve genel oarak kanal eni boyunca sinüs dalgası formunu koruduğu ancak kanal boyu boyunca 1sı geçiş katsayısının azaldığı tespit edilmiştir. Nu sayısı bakımından; G10_D50 grafiğinden anlaşılacağı gibi ısı taşınımının daha fazla olduğu Şekil 12 'de tespit edilmiştir.

Çarpan jetlerin akış ve ısı transferi özellikleri, jet çıkış geometrisi, jet çıkışındaki hız profili, jet ile plaka arasındaki mesafe, jet içerisindeki türbülans, çarpma plakası geometrisi ve jet ile plaka arasındaki sıcaklık farkı gibi birçok parametreye bağlı olarak değişmektedir. Geometrik simetriye rağmen, sıralı konfigürasyonda 1sı transferinde eliptik darbe kalıpları gözlenmiştir. Karşılıklı jet etkileşimleri nedeniyle jet distorsiyonunun bir sonucu olarak komşu jetlerin merkez jet için eliptik desen görülmüştür (Şekil 7-10). Jetler hedef plakadaki duvar jetleri haline dönüşür ve çarpışır, çarpışmanın ardından kenar kesici tabakalarda karşılıklı etkileşim ve türbülans yaratılır. Böylece güçlü olan merkezi jet komşu jeti dışarı doğru iterek bir yıkama çeşmesi ve bölgede jetler arasında devirdaimli harcanmış hava karışımı empoze eder. Bu etkileşimlerin sonucu olarak güçlü karışım oluşmakta, Nusselt sayısı da daha fazla göstermektedir. Burada tahmin edilebileceği gibi jet soğuk, çapraz akış ise sıcak gazlardan meydana gelmektedir. Çapraz akışın türbülans yoğunluğunun artmasıyla sıcak havanın akmakta olduğu kanala püskürtülen soğuk akışkan daha fazla yüzeyde etkili olmakta ve kanalın daha geniş bir yüzeyinde kendini göstermektedir (Şekil 13).

\section{KAYNAKLAR}

[1] Uysal, U., Li, P.-W., Chyu, M.K., Cunha, F.J., (2006), "Heat Transfer on Internal Surfaces of A Duct Subjected To Impingemenf of A Jet Array with Varying Jet Hole-Size and Spacing", Journal of Turbomachinery, 128,158-165.

[2] Kercher, D.M., Tabakoff, W., "Heat transfer by a square array of round air jets impinging perpendicular to a flat surface including the effect of spent air", Journal of Engineering for Power, 92: 73-82 (1970).

[3] Katti, V., Prabhu, S.V., "Influence of streamwise pitch on the local heat transfer characteristics for in-line arrays of circular jets with crossflow of spent air in one direction' Heat and Mass Transfer, 45: 1167-1184 (2009).

[4] Köseoglu, M.F., Baskaya, S., "The effect of flow field and turbulence on heat transfer characteristics of confined circular and elliptic impinging jets", International Journal of Thermal Sciences, 47: 1332-1346 (2008).

[5] Van Heinengen, A.R.P., Mujumdar, A.S., Douglas, W.J.M., "Numerical prediction of the flow field and impingement heat transfer caused by a laminar slot jet", Journal of Heat Transfer, 98: 654-658 (1976). 